\section{СХОДСТВА И РАЗЛИЧИЯ МЕЖДУ ТЮРКСКИМИ ЯЗЫКАМИ И СОПОСТАВИТЕЛЬНЫЕ МЕТОДЫ В ОБУЧЕНИИ}

\author{
Гюльзура Жумакунова \\ Университет Анкары,
} Турция

\author{
SIMILARITIES AND \\ DIFFERENCES BETWEEN \\ TURKIC LANGUAGES AND \\ COMPARATIVE METHODS \\ IN TEACHING THEM
}

\author{
Gyulzura Zhumakunova \\ Ankara University, \\ Turkey
}

\begin{abstract}
Тюркские языки - это родственные языки, восходящие к единому языку-основе - пратюркскому языку. В результате сложной длительной истории тюркоязычных народов все тюркские языки приобрели, в той или иной мере, изменения на всех (фонемном, морфемном, лексическом, синтаксическом) уровнях. В то же время тюркские языки сохранили общие черты, которые ведут к единому языку-основе. В статье автор, основываясь на собственном многолетнем опыте работы преподавателя кыргызского языка в Университете Анкары, излагает свое видение в обучении тюркским языкам в целом, описывает те подходы и приемы обучения, которые, на её взгляд, помогают в успешном обучении студентов.

При обучении тому или иному тюркскому языку главная цель состоит не в том, чтобы изучить другой язык, а как бы совершить увлекательное путешествие по неизвестным тропам своего родного языка, познать его ещё глубже, в его исторической ретроспективе. Тюркские языки всегда привлекали внимание мировых ученых-лингвистов, активно исследовались. Ознакомление студентов с различными научными теориями, с работами видных ученых-тюркологов, как показывает практика, тоже очень помогает в формировании у студентов устойчивого интереса и стремления
\end{abstract}

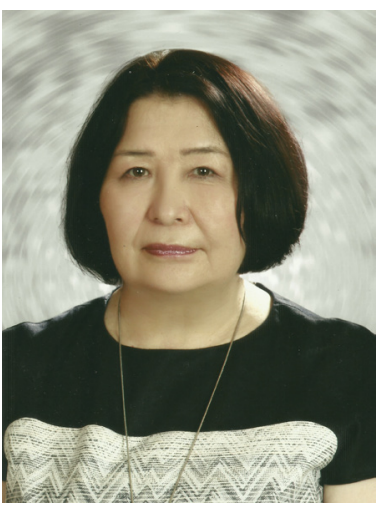

Turkic languages are cognate language which stem back to the single ancestor - ProtoTurkic language. In the course of long and convoluted history of Turkic-speaking peoples, all of their languages suffered various degrees of change on every level of its structure - in phonemes, morphemes, vocabulary and syntax. At the same time, all of these languages have preserved some of their common features which link them to their ancestor tongue. In this article, the author, from her long experience of teaching Kyrgyz at Ankara University, explains her vision of teaching Turkic languages in general and describes the methods and approaches which she deems helpful in successful teaching on university level.

In teaching a Turkic language, the main objective is not to focus on language study as such, but take a breathtaking journey along the hidden paths of one's mother tongue and get to understand it in a more profound way, in its historical retrospective. Turkic languages have always attracted linguists and were in the focus of their studies. Getting acquainted with various linguistic theories and the works of prominent Turkologists, as seen from

Жумакунова Гюльзура - доктор филологических наук, профессор кафедры тюркских языков и литератур, Университет Анкары. Адрес: Şemsettin Günaltay Cad. 303. Sok. 2/3, Kırkkonaklar, Çankaya Ankara 06700. Тел.: +90 31231032 80. Эл. адрес: gulzura@gmail.com

Zhumakunova Gyulzura, Doctor of Philology, Professor, Department of Turkic Languages and Literatures, Ankara University. Postal address: Şemsettin Günaltay Cad. 303. Sok. 2/3, Kırkkonaklar, Çankaya Ankara 06700. Tel.:+90 31231032 80. Email: gulzura@gmail.com 
познать как изучаемый язык, так и свой родной, глубже и шире.

Необходимо учитывать такие экстралингвистические факторы, как цель обучения, приемлемость окружающей среды и степень необходимости изучения языка в данной среде. Это рассмотрено на примере алфавитов, употребляемых по-разному среди тюркских народов. При подготовке программы обучения языка очень важна и степень знакомости аудитории с иелевым языком.

В цеелом, работа признана новой, требующей основательной разработки методологических и научно-методических основ, подготовки разного типа академических и учебных словарей, учебных пособий, которые будут помогать изучающим тот или иной тюркский язык.

Ключевые слова: тюркский язык; тюркский народ; кыргызский язык; проблемы преподавания; Туриия; методика обучения teaching practice, is also very helpful to shape an enduring interest in learning both the target language and first language more profoundly.

We also have to take into account such extralinguistic factors as the objective of language study, friendliness of the environment and the demand for language in a given environment. The article examines these issues through the alphabets and their various uses among Turkic peoples. When setting up a language study program, it is also important to take into account how familiar students are with the target language.

Overall, this new type of work required a fundamental study of methodological foundations of language teaching. New types of academic and learners' dictionaries have to be prepared, as well as new textbooks to help students of a specific Turkic language.

Keywords: Turkic language; Turkic peoples; Kyrgyz language; problems of teaching language; Turkey; methods of teaching

\section{Введение}

Падение «железного занавеса» в конце 1980-х - в начале 1990-х годов открыло путь к более активному и разностороннему общению и сотрудничеству между разными государствами и народами в различных сферах и областях, в том числе науке. В тюркологии это выразилось в расширении тематических направлений, углублении теоретических основ и проблем, активации экспедиционных исследований с целью сбора и последующего сравнительно-сопоставительного анализа материалов по языку, фольклору, истории, этнографии и т. д. тюркоязычных этносов, проживающих на разных континентах и на территориях разных государств. Также это проявилось в актуализации преподавания тюркских языков как учебных дисциплин, владения тем или иным тюркским языком или языками не только дипломатами и специалистами в области тюркологии, но и просто желающими. В связи с этим значительно расширился круг учебных заведений, где стали преподавать те или иные тюркские языки.

Первым учебным заведением, где открыли в 1992 г. кафедру современных тюркских языков и литератур, стал Университет Анкары (Ankara Üniversitesi) в Турции. Вслед за ним в разные годы открылись подобные кафедры и в других турецких университетах. Я в течение довольно долгого времени (25 лет) работаю преподавателем кафедры современных тюркских языков и литератур Университета Анкары, учу студентов отделения «Северо-западные (кипчакские) тюркские языки и литературы» кыргызскому языку. За столько лет работы мною были опробованы разные подходы, формы и приемы обучения. 
В ходе практической работы и как преподавателя, ведущего аудиторные занятия, и как научного руководителя по подготовке магистерских и кандидатских диссертаций у меня выработалось собственное видение преподавания кыргызского и других родственных языков турецким. Основная масса обучающихся - это граждане Турции. Редкое исключение, по одному-два человека на набор, составляют те, кто приехал из других стран по межгосударственным программам обмена студентами и аспирантами. В данной статье я вкратце остановлюсь на обобщении своих наблюдений относительно тех подходов и приемов обучения, которые помогают в успешном обучении студентов.

\section{Основные подходы, формы и приемы обучения}

Кыргызский язык (самоназвание - кыргыз тили, кыргызча) относится к тюркским языкам, которые представляют собой большую разветвленную систему родственных языков, восходящих к единому языку-основе - пратюркскому языку.

В процессе исторического развития у всех тюркских языков образовались диалекты и говоры, на всех (фонемном, морфемном, лексическом, синтаксическом) уровнях произошло много изменений под воздействием тех контактов и связей, в которые вступали их носители-этносы по пути миграции и освоения тех или иных территорий (Батманов, 1963; Юнусалиев, 1966; Орузбаева, 1997). Здесь также не следует забывать и о таких факторах, как наличие или отсутствие государственного строя, уровень развития общества и др., которые играют большую роль в расширении сфер функционирования языка, и, следовательно, в формировании разных его форм и стилей, в его развитии в целом. Как результат всех перипетий, через которые прошли тюркские народы с тех пор, как начали мигрировать, распространяться за пределы их исторического ареала и интегрироваться с разными народами, перед нами предстает интересная картина взаимоотношений тюркских языков. С одной стороны, из-за приобретенных со временем изменений на уровне фонетики, лексики, морфологии и синтаксиса представители разных тюркских народов испытывают, в той или иной мере, затруднения при общении. С другой стороны - тюркские языки обнаруживают такие общие черты, которые ведут к единому языку-основе.

Поэтому при обучении тому или иному тюркскому языку главная цель состоит не в том, чтобы изучить другой язык, а как бы совершить увлекательное путешествие по неизвестным тропам своего родного языка, познать его ещё глубже, в его исторической ретроспективе и в том виде, в каком он сложился к настоящему времени. Для этого преподавателю, объясняя каждую тему, нужно привлекать как можно больше сравнительно-сопоставительного материала, чтобы студенты имели возможность детально определить степень отличительных и общих черт изучаемых родственных языков. 
Использование именно такого подхода помогало и помогает мне в том, чтоб обучаемые мною студенты в целом осваивали кыргызский язык на том уровне, чтобы могли разговаривать, изъясняться, читать различные тексты, в том числе литературно-художественные, а в некоторых случаях - продолжить изучение кыргызского языка уже на уровне исследователя и преподавателя высшей школы.

Тюркские языки всегда привлекали внимание мировых ученых-лингвистов, активно исследовались ввиду того, что имеют очень древнюю письменную традицию, широко распространены в разных частях света и в каждом своем проявлении, будь то якутский язык или турецкий, чрезвычайно интересны и уникальны. В настоящее время существует огромное количество исследований, в том числе относительно классификации тюркских языков, степени их родства с другими языковыми семьями (алтайская макросемья или урало-алтайская макросемья), грамматик, словарей, диссертаций, и в этом плане тюркские языки нисколько не отстают от любой языковой семьи мира (Баскаков, 1962; Гаджиева, 1997; Тенишев, 1984, 1988, 1997, 2006). Ознакомление студентов с различными научными теориями, с работами видных ученых-тюркологов, как показывает практика, тоже очень помогает в формировании у студентов устойчивого интереса и стремления познать как изучаемый язык, так и свой родной, глубже и шире.

Преподавание языка, независимо от того, родной он или иностранный, - это двустороннее общение, работа, направленная прежде всего на привитие навыков разговорной речи, и такие правила, как полная упорядоченность описания языка, строгая логизированность и последовательность изложения материала, книжность, которые больше характерны для научных исследований, здесь могут и не быть на переднем плане. Больше общения и практических работ, заданий, при выполнении которых обучаемый работает с желанием и интересом, - одно из непременных условий преподавания языка, пусть он даже одного корня с языком обучаемого.

Как известно, результат изучения языка зависит, наряду с физиологическими факторами, от психологического состояния обучаемого. Поэтому необходимо учитывать такие экстралингвистические факторы, как цель обучения, приемлемость окружающей среды и степень необходимости изучения языка в данной среде.

Попытаемся рассмотреть это на примере алфавитов, употребляемых поразному среди тюркских народов.

Алфавит - это набор символов, расположенных в определенной последовательности. Он считается внеязыковым фактором, который не имеет прямой связи с сущностью языка. Но его роль в преподавании языка велика. То, что кыргызы и турки пользуются разными алфавитами, создает большие проблемы в учебном процессе. Одно и то же слово из общетюркской лексики, написанное разными символами на кириллице и латинице, не вызывает одинаковой 
коннотации у учащихся. Именно из-за этого изучение кыргызского алфавита занимает много времени у студента-турка. Однако гораздо быстрее осваивает кыргызский алфавит русский студент, который разделяет тот же алфавит со студентом-кыргызом. Однако, здесь нужно обязательно подчеркнуть, что орфография кыргызского языка, основанная на русском правописании, тоже играет немаловажную роль в его быстром и успешном изучении.

При подготовке программы обучения языка очень важна и степень знакомости аудитории с целевым языком. Например, программа, подготовленная для русской аудитории, которая является представителем флективного языка, должна отличаться от программы, подготовленной для тюркской аудитории, которая является представителем агглютинативного языка. В русской аудитории необходимо следовать методу, основанному на различных звуковых правилах, различных грамматических структурах, различных шаблонах предложений и на совершенно другой словарный запас. Кыргызский и русский языки имеют только общий алфавит и некоторую общую лексику, возникшую в результате многолетнего сосуществования.

Золотое правило, которое должно быть подчеркнуто и учтено в преподавании языков, относящихся к одной языковой семье, - это необходимость внедрения в сознание обучаемых общность изучаемого и родного языков, их звуковых и грамматических правил, структуры предложения и лексического состава. Следует объяснить, что язык, который он изучает, не иностранный, а одного и того же происхождения с его родным языком. Поэтому преподавателю надо хорошо знать сходства и различия между его родным языком и тем, что он преподает, и подготовить свою программу соответственным образом.

Турецкий и кыргызский языки, которые входят в огузскую и кипчакскую группы тюркских языков, в течение сотен лет не имели тесной связи между собой и, следовательно, у них со временем сформировалось немало отличительных черт на разных уровнях. Если еще вспомнить о том, что кыргызский язык по своим фонетическим и грамматическим свойствам, а также по запасу устаревших слов более схож с языками северо-восточной (сибирской) подгруппы, которые имеют большую степень отличия от турецкого, то степень различия значительно возрастет (Жусупакматов, 1983).

Как известно, самым изменчивым слоем языка является его словарный запас. Различия словарного состава кыргызского и турецкого языков в общем связаны с некоторыми объективными причинами.

Мы можем перечислить эти различия следующим образом:

- Разные формы одних и тех же слов, образовавшиеся в результате различных фонетических изменений (долгие гласные, свойственные кыргызскому языку, стабильность гармонии гласных и согласных и вытекающее из этих законов многовариантность словоизменяющих и словообразующих суффиксов и т. д.); 
- Слова и фразеологизмы, выражающие разные значения;

- Отличительные особенности, образовавшиеся под влиянием разных географических, экономических условий и социальных факторов. Например, турецкий язык долгое время оставался под влиянием арабского, персидского и французского языков, а кыргызский - под влиянием русского языка;

- Турецкий язык постоянно обогащался за счет своих внутренних и внешних ресурсов. В нем механизмы словообразования и словообразования всегда функционировали активно, чтобы отвечать требованиям литературного языка, тогда как кыргызы и другие тюркские народы предпочли заимствовать слова напрямую или же путем калькирования из русского языка.

Тем не менее, когда мы несколько лет назад начали готовить словарь общих слов кыргызского и турецкого языков, нами было обнаружено, что сорокатысячный кыргызский словарь имеет около семи тысяч турецких эквивалентов. Мало ли это, много ли? Возможно, этого мало по критериям классификации тюркских языков. Глядя на эти данные, можно определить их как тюркские языки с очень дифференцированными лексическими составами. Но, на наш взгляд, этого достаточно для взаимного обучения этим языкам и извлечения из этой общности определенной выгоды на максимальном уровне. Более того, если принять во внимание то, что эти семь тысяч слов составляют базисную основу общетюркской лексики в таких тематических группах, как названия частей тела, цветов, терминов родства, названий основных продуктов питания, флоры и фауны, цифр, направлений света, отрезков времени, частей пространства и т. д., становится ясным, каким общим арсеналом слов мы владеем (Cumakunova, 2005).

На первом этапе обучения должны часто применяться общие слова для того, чтобы у обучающего появился интерес к языку, который он начал изучать, и чтобы он осознал, что открывает дверь нового, но родственного мира. Через некоторое время, когда происходит переход от общего к отличительным чертам, учащиеся будут рассуждать, анализировать, исследовать природу произошедших изменений.

Несмотря на то что в области фонетики кыргызского и турецкого языков такие базовые данные, как общая звуковая структура, основные фонетические правила, структура слога и некоторые интонационные особенности одинаковы, кыргызский язык отличается от турецкого по некоторым параметрам фонетики, в частности по наличию долгих гласных (аa, ээ, оо, өө, уу, үY), стабильности полной гармонии гласных, прогрессивной и регрессивной ассимиляции согласных, а также отсутствию озвончения некоторых твердых /т/ и /ч/ согласных.

Большинство этих различительных черт развивались на основе действующих фонетических правил. Причины вполне объяснимы в рамках законов звуковой системы обоих языков, которые мы можем назвать внутренними отличиями. 
Поэтому их следует объяснить студентам на соответствующих примерах или же сравнением аналогичных образцов.

Основные общие черты между турецким и кыргызским языком в области морфологии обнаруживаются в основном в корнях имён существительных, глаголов, числительных, прилагательных, обозначающих цвета, личных и указательных местоимений. Что касается имяобразующих аффиксов, особенно образующих имя от имени и имя от глагола, тоже нет большой разницы. По этой причине у учащихся не возникает особых трудностей при словообразовании или же морфемном разборе слов.

Но при спряжении глаголов по лицам, числам и временам возникают довольно серьезные проблемы. В турецком и кыргызском языках полностью совпадает только прошедшее время на $-\partial u /-d i$. По этой причине удобнее и эффективнее начинать изучение глагольных категорий с прошедшего времени на $-\partial u /-d i$, используя его в качестве ввода в тему с постепенным переходом к другим, имеющим некоторые отличия, формам.

По каждой теме, по каждому разделу языка можно найти то, на что опереться в начале, заинтересовать студентов, стимулировать их в успешном изучении выбранного языка.

\section{Заключение}

Вопрос, который был затронут в данной статье, разумеется, невозможно решить в рамках одной работы.

Преподавание языка, в том числе родственного родному, - тема многогранная и сложная. Если раньше, до 1990-х годов, преподавание тюркских языков, причем только некоторых из них, ограничивалось в основном вузами, где готовили дипломатов, то теперь, конечно, ситуация несколько изменилась. Тюркские языки или их часть преподаются в ряде университетов Турции, Казахстана, Кыргызстана, России и т. д. Они входят в программу языковых курсов и школ, функционирующих в тех или иных республиках, городах. Тем не менее это работа довольно новая, и она требует основательной разработки методологических и научно-методических основ, подготовки разного типа академических и учебных словарей, учебных пособий, которые будут помогать изучающим тот или иной тюркский язык.

В этом успешно могут сотрудничать как ученые-теоретики в области тюркологии, так и преподаватели-практики. Взаимное изучение однозначно обогатит каждый язык, не говоря уже о конкретном индивидууме, который одолел «тернистый путь» овладения ещё одним языком. Ведь трудно усомниться, особенно в наше время - время открытости и глобализации, в правдивости и истинности широко распространенного выражения «Сколько языков ты знаешь, столько раз ты человек». 


\section{СПИСОК ЛИТЕРАТУРЫ}

Баскаков, Н. А. (1962) Введение в изучение тюркских языков. М. : Высшая школа. 331 с.

Баскаков, Н. А. (1966) Тюркские языки (общие сведения и типологическая характеристика) // Языки народов СССР. М. : Наука. Т. 2. Тюркские языки. 529 с.

Батманов, И. А. (1963) Современный киргизский язык. Фрунзе : Изд-во АН Киргиз. ССР. 165 с.

Гаджиева, Н. 3. (1997) Тюркские языки // Языки мира. Тюркские языки. М. : Индрик. 543 с.

Жусупакматов, Л. (1983) Отношение киргизского языка к сибирским тюркским языкам. Фрунзе : Илим. 139 с.

Орузбаева, Б. О. (1997) Киргизский язык // Языки мира. Тюркские языки. М. : Индрик. 543 с.

Тенишев, Э. Р., Гаджиева, Н. З., Серебренников, Б. А. и др. (1984) Сравнительно-историческая грамматика тюркских языков. Фонетика. М. : Наука. 483 с.

Тенишев, Э. Р., Аракин, В. Д., Благова, Г. Ф. и др. (1988) Сравнительно-историческая грамматика тюркских языков. Морфология. М. : Наука. 423 с.

Тенишев, Э. Р., Гаджиева, Н. З., Серебренников, Б. А. и др. (1986) Сравнительно-историческая грамматика тюркских языков. Синтаксис. М. : Наука. 283 с.

Тенишев, Э. Р., Благова, Г. Ф., Добродомов, И. Г. и др. (1997) Сравнительноисторическая грамматика тюркских языков. Лексика. М. : Наука. 799 с.

Тенишев, Э. Р., Благова, Г. Ф., Добродомов, И. Г., Дыбо, А. В. и др. (2006) Сравнительно-историческая грамматика тюркских языков. Пратюркский язык-основа. Картина мира пратюркского этноса по данным языка. М. : Наука. 908 с.

Юнусалиев, Б. М. (1966) Киргизский язык // Языки народов СССР. М. : Наука. Т. 2. Тюркские языки.529 с.

Cumakunova, G. (2005) Türkçe-Kırgızca Sözlük [Турецко-кыргызский словарь]. Bişkek : KTMU Yayınları. $1000 \mathrm{~s}$.

Дата поступления: 12.01.2018 2.

\section{REFERENCES}

Baskakov, N. A. (1962) Vvedenie v izuchenie tiurkskikh iazykov [Introduction into the Study of Turkic Languages]. Moscow, Vysshaia shkola. 331 p. (In Russ.). 
Baskakov, N. A. (1966) Tiurkskie iazyki (obshchie svedeniia i tipologicheskaia kharakteristika) [Turkic Languages: General Information and Typological Characteristics)]. In: Iazyki narodov SSSR [The Languages of the Peoples of the USSR]. Moscow, Nauka. Vol. 2. Tiurkskie iazyki [Turkic language]. 529 p. (In Russ.).

Batmanov, I. A. (1963) Sovremennyi kirgizskii iazyk [Contemporary Kyrgyz Language]. Frunze, AN Kirgiz. SSR Publ. 165 p. (In Russ.).

Gadzhieva, N. Z. (1997) Tiurkskie iazyki [Turkic Languages]. In: Iazyki mira. Tiurkskie iazyki [Languages of the World. Turkic Languages]. Moscow, Indrik. 543 p. (In Russ.).

Zhusupakmatov, L. (1983) Otnoshenie kirgizskogo iazyka k sibirskim tiurkskim iazykam [The Relations between Kyrgyz Language and Siberian Turkic Languages]. Frunze, Ilim. (In Russ.).

Oruzbaeva, B. O. (1997) Kirgizskii iazyk [Kyrgyz Language]. In: Iazyki mira. Tiurkskie iazyki [Languages of the World. Turkic Languages]. Moscow, Indrik. 543 p. (In Russ.).

Tenishev, E. R., Gadzhieva, N. Z., Serebrennikov, B. A. et al. (1984) Sravnitel'no-istoricheskaia grammatika tiurkskikh iazykov. Fonetika [A Comparative Historical Grammar of Turkic Languages: Phonetics]. Moscow, Nauka. 483 p. (In Russ.).

Tenishev, E. R., Arakin, V. D., Blagova, G. F. et al. (1988) Sravnitel'no-istoricheskaia grammatika tiurkskikh iazykov. Morfologiia [Comparative-historical grammar of Turkic languages. Morphology]. Moscow, Nauka. 423 p. (In Russ.).

Tenishev, E. R., Gadzhieva, N. Z., Serebrennikov, B. A. et al. (1986) Sravnitel'no-istoricheskaia grammatika tiurkskikh iazykov. Sintaksis [A Comparative Historical Grammar of Turkic Languages: Syntax]. Moscow, Nauka. 283 p. (In Russ.).

Tenishev, E. R., Blagova, G. F., Dobrodomov, I. G. et al. (1997) Sravnitel'no-istoricheskaia grammatika tiurkskikh iazykov. Leksika [A Comparative Historical Grammar of Turkic Languages: Vocabulary]. Moscow, Nauka. 799 p. (In Russ.).

Tenishev, E. R., Blagova, G. F., Dobrodomov, I. G., Dybo, A. V. et al. (2006) Sravnitel'no-istoricheskaia grammatika tiurkskikh iazykov. Pratiurkskii iazyk-osnova. Kartina mira pratiurkskogo etnosa po dannym iazyka [A Comparative Historical Grammar of Turkic Languages: The Proto-Turkic Ancestor Language. The World Picture of Proto-Turks according to Their Language]. Moscow, Nauka. 908 p. (In Russ.).

Iunusaliev, B. M. (1966) Kirgizskii iazyk [Kyrgyz Language]. In: Iazyki narodov SSSR [The Languages of the Peoples of the USSR]. Moscow, Nauka. Vol. 2. Tiurkskie iazyki [Turkic Languages]. 529 p. (In Russ.).

Cumakunova, G. (2005) Türkçe-Kırgızca Sözlük [A Turkish-Kyrgyz Dictionary]. Bişkek, KTMU Yayınları. 1000 p. (In Turkish and Kyrgyz).

Submission date: 12.01.2018. 


\section{Для цитирования:}

Жумакунова Г. Сходства и различия между тюркскими языками и сопоставительные методы в обучении [Электронный ресурс] // Новые исследования Тувы. 2018, № 1. URL: https://nit.tuva.asia/nit/article/view/759 (дата обращения: дд.мм.гг.). DOI: 10.25178/nit.2018.1.9

\section{For citation:}

Zhumakunova G. Similarities and differences between Turkic languages and comparative methods in teaching them. The New Research of Tuva, 2018, no. 1 [on-line] Available at: https://nit.tuva.asia/nit/article/view/759 (accessed: ...). DOI: 10.25178/ nit.2018.1.9 